\title{
Adaptability of triangular TL tower design with Schifflerized angle sections
}

\author{
B.Ramesh ${ }^{1}$, Balaji, K.V.G.D ${ }^{2}$, B. Santhosh Kumar ${ }^{3}$ \\ ${ }^{1}$ Assistant Professor, Department of Civil Engineering, GITAM University, Visakhapatnam, Andhra Pradesh, \\ India, rbantupa@gitam.edu \\ ${ }^{2}$ Professor, Department of Civil Engineering, GITAM University, Visakhapatnam, Andhra Pradesh, India \\ ${ }^{3}$ Deputy Executive Engineer, W.R. Department, Vizianagaram, India
}

\begin{abstract}
The triangular shape towers have been widly used in transmission line towers. Generally, the profile legs are designed with either angular sections or tubular sections. As the triangular tower vertices are inscribed at $60^{\circ}$ internal angle, the connection between the bracings and the profile legs can be achieved by bending $15^{\circ}$ inward either the gusset plate or the angle of the profile leg. The manufacturing process of hot rolled $60^{\circ}$ is not yet developed fully, the other alternative of schifflerized angle sections have been adopted in the design of the $60 \mathrm{~m}$ height Transmission Line tower design. The IS 802 code procedure stipulates the design requirements of TL Towers.However, no special provision for schifflerized angle sections has been made in this code. The Canadian Standardcode- (CSA S16-09) has specified the distinctive provisions for the design of schifflerized sections. The relevant buckling strength equations of Canadian standard and IS 802-2016 are approximately the same. Hence strength and economic viability of schifflerized angle sections with conventional $90^{\circ}$ angle section of the 60-meter tower with broken wire conditions for a span 250 meter have been explored with E-tabs software that the $10 \%$ weight savings have been achieved with the schifflerized angle sections for the same strength of the conventional angle sections.
\end{abstract}

Keywords: E-TABS software, IS 802, schifflerizedAngle. CSA-S16-09, TL Tower,

\section{INTRODUCTION}

The exponential developments in the transmission and telecommunication sectors require a large-scale free-standing lattice tower $[1,2]$. These towers are formed as a square or triangular base with convergent up to $34^{\text {th }}$ height and the remaining top profile is parallelepiped shape. Conventional Hot-rolled $90^{\circ}$ steel equal angle sections are generally used in latticed towers for leg members, primary bracings and redundant or secondary bracings.

With the economic point of view, the triangular shape towers are also adopted duly commensurable with the safety of the system[3]. The triangular shape towers are classified as 'Hybrid Towers' and 'Angular Section Towers'. The profile legs of the hybrid towers are designed with pipe sections and the bracings are either angle or pipe sections and the bracing members are either angle or pipe sections.

The bracing members of the rectangular towers are directly connected to the main leg members with and without the usage of the gusset plates. This can be easily achieved since the bracing planes, as well as the main leg members, are laid at the right angle to each other. However, for triangular-base towers, the bracing planes intersect at $60^{\circ}$ to each other.

The angle sections of profile legs of triangle towers are connected to the bracing members with the two options. In the first option, the profile legs and the bracing members are connected through $15^{0}$ bent up gusset plates. Secondly, a portion of profile leg bent inward by $15^{0}$ to produces the required $60^{\circ}$ angle to directly connect the bracing members, which is known as the schifflerized angel member [4]. The process involves either re-rolling or brake-pressing a regular $90^{\circ}$ angle.The finished member is called a schifflerized angle. This process increases the moment of inertia of the cross-section about the minor principal axis. Consequently, the member is stronger in flexural buckling and is slightly weaker in torsional- flexural buckling when compared to the regular $90 \mathrm{o}$ angle member [4].

The conventional angle section fails by flexural buckling about the asymmetric minor principal axis of inertia. The strength of the compression members depends on the strength of the material and the length of the member. Primarily the buckling strength of the longer member is smaller than the shorter member, which was due to the effective slenderness ratio. Thus a redundant / cross bracing member connected to the main member at an intermediate point can change the buckling strength of full member from minor axis to major axis and increase its buckling strength significantly.

Buckling has been described as the behaviour of the structure /structural element suddenly deforms in a plane different from the original plane of loading and response [5]. Flexural 
B.Ramesh et al., International Journal of Emerging Trends in Engineering Research, 8(10), October 2020, 6961 - 6968

torsional buckling is a mode of buckling consists of both deflection and twisting. It depends on the Warping mode of deformation where the plane sections don't remain plane. Flexural torsional buckling primarily reduces the load-carrying capacity of the steel members. Local buckling occurs if the width-to-thickness ratio or diameter-to-thickness ratio of a section exceeds a certain value.

The schifflerizing process, while bending the legs inward by $15^{\circ}$ each, cannot deform the heel (or root) portion of the original regular angle because of its high rigidity. As a result, every $60^{\circ}$ angle member will have a $90^{\circ}$ unchanged root portion of length ranging from 16 to $40 \mathrm{~mm}$ depending upon the leg thickness [4].Strength and behaviour of these angles will be different from the regular $90^{\circ}$ angle members.

Although schifflerized angles have been in use for many decades, the published literature is very scanty about the behaviour for TL tower geometry with broken wire conditions. Hence this paper attempted to find the adaptability of the design strength of the schifflerized angle profile members on the $60 \mathrm{~m}$ height of TL tower double circuit with $250 \mathrm{~m}$ basic span in the wind zone 5 of India. And secondly, a comparison with the square legged tower also made to find the economic viability of the structure.

\section{LITERATURE REVIEW}

The historical development of the schifflerized angle sections geometric properties are incepted from the [4]and computed the geometrical properties form the largest section $200 \times 200 \times 30 \mathrm{~mm}$ to the smallest section $60 \times 60 \times 5 \mathrm{~mm}$.A comparative study of CSA standard S37-9with ASCE10-90 design parameters for computing the buckling capacity of Schifflerize angles has been studied and highlighted the conservation of CSA Standard[6].

The torsional and flexural loading buckling load capacity of Schifflerized angles have been experimentally found when $w / t$ ratio is less than 13 and greater than 15 respectively[7].It is found that the strength of schifflerized angles has $20 \%$ higher strengths when compared to the $90^{\circ}$ angles [8].The flexural-torsional buckling failure mode doesn't govern the critical for computing the compressive capacity of Angles subject to axial compression because of them that the shear modulus $\mathrm{G}$ remains unchanged when part of the angle section yields and that local buckling takes place beforehand in angles of high strength steel with the slender leg[9].The replacement of the unbent width to replace with the flat width represents the better results for computations with ASCE -1997 methodology[10].

It is further noted that the energy methods in the second-order analysis render the estimation of strength in the range of 5-12\% less[11].The open section members when bent in the stiffer principal plane may suddenly buckle out of that plane because low torsional and warping constants[12].

The advantage of new generation conductors on the safety of transmission tower designs for the monopole towers was examined that the significant advantages were observed with the new generation conductors [13]. The computational methods of the Wind loads on Free lattice towers are deliberated in [14-15].Different methods of software programmes for the Transmission towers have been found[16-17].

\section{METHODOLOGY}

\subsection{Modelling of the tower:}

Schifflerized angle sections are modelled using 'sections designer' in E-TABS[18] as shown in Figure and a typical Schifflerized angle section was shown in the Figure2.

The geometric properties of the $60 \mathrm{~m}$ high TL tower parameter are shown in the table1.

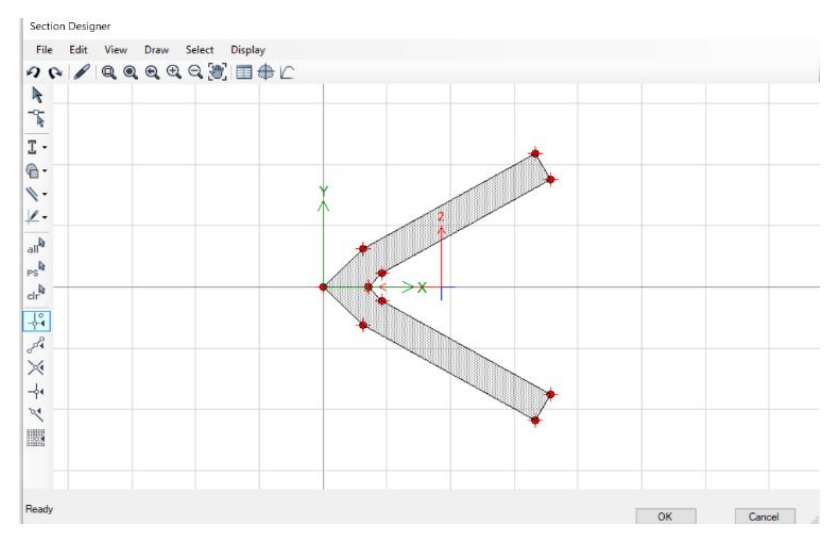

Figure 1: Maximum Section size modelled in E-Tabs Section Designer 200x200x30

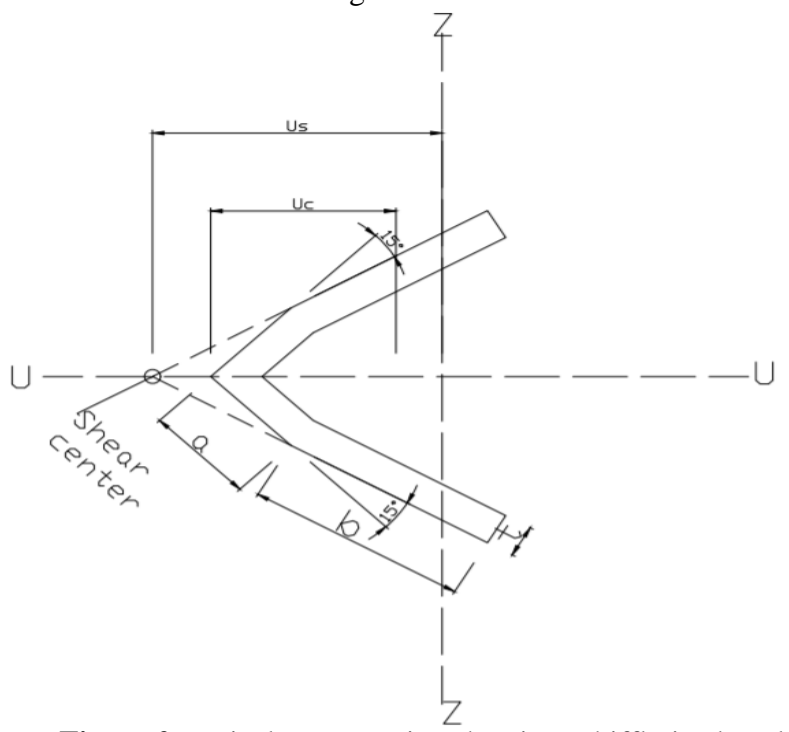

Figure 2 Typical cross-section showing schifflerized angle

Table 1: Geometrical properties of schifflerized angle section

\begin{tabular}{|c|c|c|}
\hline $\begin{array}{c}\text { Geometric } \\
\text { properties }\end{array}$ & $\begin{array}{c}\text { Three-legged } \\
\text { tower using } \\
\text { Schifflerized } \\
\text { sections }\end{array}$ & $\begin{array}{c}\text { Three-legged } \\
\text { tower using } \\
\text { Conventional } \\
\text { Angle sections }\end{array}$ \\
\hline $\begin{array}{c}\text { Height of the } \\
\text { tower(m) }\end{array}$ & 60 & 60 \\
\hline
\end{tabular}


B.Ramesh et al., International Journal of Emerging Trends in Engineering Research, 8(10), October 2020, 6961 - 6968

\begin{tabular}{|c|c|c|}
\hline $\begin{array}{c}\text { Height of the slant } \\
\text { portion(m) }\end{array}$ & 45 & 45 \\
\hline $\begin{array}{c}\text { Height of the Straight } \\
\text { portion at the top (m) }\end{array}$ & 15 & 15 \\
\hline Base width (m) & 13 & 13 \\
\hline Top width (m) & 2.2 & 2.2 \\
\hline
\end{tabular}

The Conventional angle sections comprise from a minimum section of $55 \times 55 \times 5 \mathrm{~mm}$ to a maximum section of $200 \times 200 \times 30 \mathrm{~mm}$. Similar schifflerized sections have been adopted from the section database of the [4]. The sectional properties such as area, Moment of Inertia about the major and minor axis, the radius of gyrations, and the relevant properties are found by the closed-form solutions(4) in excel sheets. Similarly, the equivalent geometric properties were extracted from the E-Tabs output files.

\subsection{Loading details:}

The wind loads on the tower, insulators and the conductor are the primary loadings for the design of the transmission towers. This loading condition is adopted from the IS 802(part1/sec1)-2015 code recommendations with Gust factor method[19]. The regional wind speeds, risk factor and terrain and height factors are the wind speed multipliers for computing the wind speed. Later the wind pressure was found with these factors, and finally, the panel loads were computed with the solidity ratio in terms of force coefficients. The variations are shown in the figures3-4.

Transverse wind loading condition is considered for calculating the wind loads on the conductors for the half of the basic span of the conductor on either side of the tower as the towers are considered on level ground. This load is loaded at the conductor arm level. The longitudinal load at the conductor point is considered on one side of the spawn point as a broken wire condition of the conductor is taken as the critical load for torsion mode of failure load.

\section{RESULTS:}

After applying the wind loads on the panel point on the tower, transverse wind loading on the conductor and longitudinal loading of the conductor as a broken wire condition with the loading procedure of IS 802 Part 1( Sec 1\& 2[19], and importing the geometrical schifflerized angles and the conventional angle sections. The tower was analyzed with as a space frame truss element model in E-tabs software programme. The load-carrying capacity of schifflerized angle sections and conventional angles are found after passing the optimization of a section utilization ratio.

To comply with the geometrical properties of schifflerized angle sections with the closed-form solution [4] a comparison is made with the generated properties in E-Tabs software programme. The sectional properties including $\mathrm{C} / \mathrm{S}$ area, Moment of Inertia about the major axis, Minor axis, the radius of gyration and polar moment inertia are compared. '

The gust loading factor method was adopted for designing the TL tower with transfer wind loads on the conductor, tower body, and the broken wire condition of the conductor is

considered for maximum torsional load effect on the tower. The variation of the Gust factor, variation of wind speed factors are depicted in the figures.

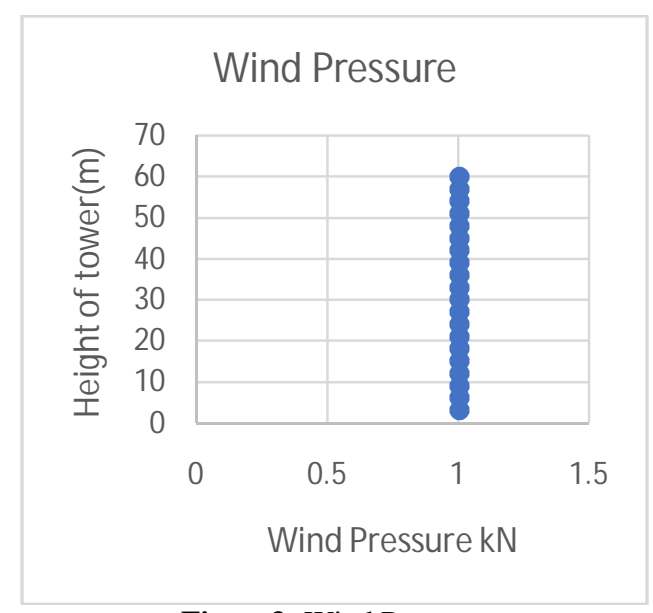

Figure3: Wind Pressure

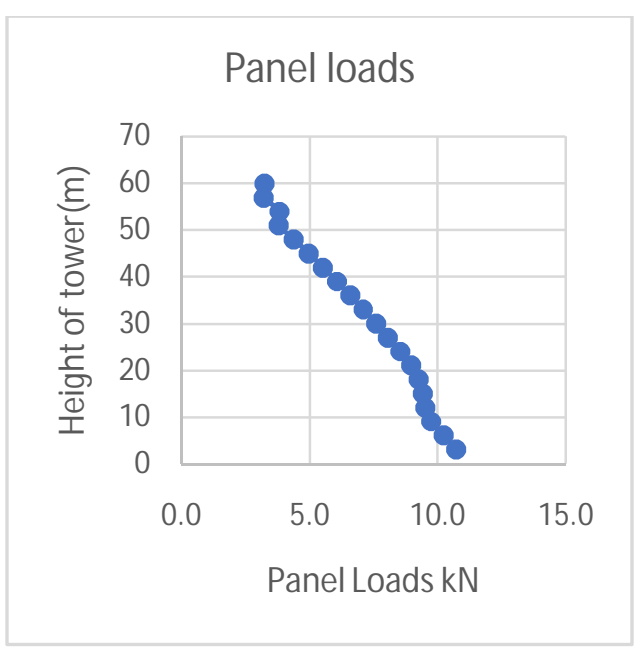

Figure 4: Panel Loads

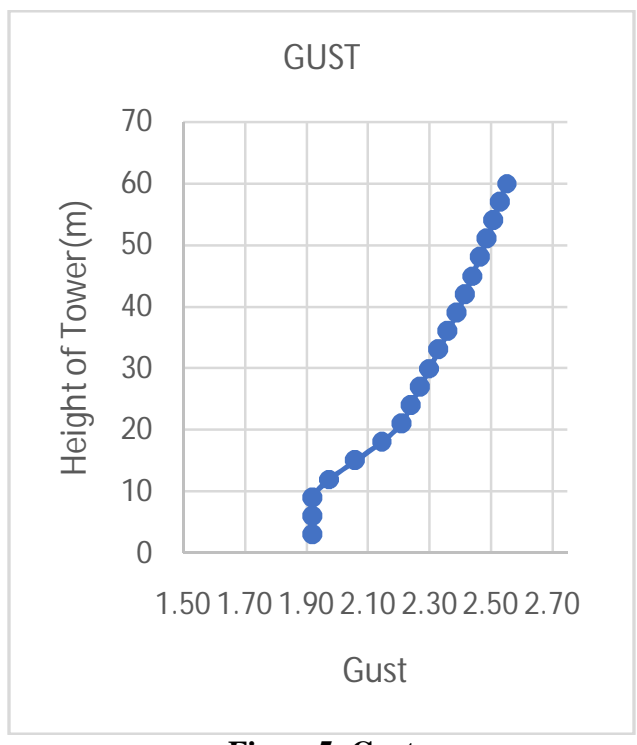

Figure5: Gust 
B.Ramesh et al., International Journal of Emerging Trends in Engineering Research, 8(10), October 2020, 6961 - 6968

Table 2: Compression of Geometrical Properties with E-Tabs

\begin{tabular}{|c|c|c|c|c|c|c|}
\hline & \multicolumn{3}{|c|}{ SCF 55X8 } & \multicolumn{3}{c|}{ SCF 200X30 } \\
\hline $\begin{array}{c}\text { Geometric } \\
\text { Property }\end{array}$ & Equation & E-Tabs & $\begin{array}{c}\text { Percentage } \\
\text { variation }\end{array}$ & Equation & E-tabs & $\begin{array}{c}\text { Percentage } \\
\text { variation }\end{array}$ \\
\hline Area & 8.0 & 8.16 & $2 \%$ & 108.60 & 111.00 & $2 \%$ \\
\hline Iuu & 26.0 & 27.63 & $6 \%$ & 3828 & 4103.14 & $7 \%$ \\
\hline Ivv & 11.40 & 11.72 & $3 \%$ & 2240 & 2302.2 & $3 \%$ \\
\hline ruu & 18.00 & 18.40 & $2 \%$ & 59.40 & 60.79 & $2 \%$ \\
\hline rvv & 11.90 & 11.97 & $1 \%$ & 45.40 & 45.54 & $0 \%$ \\
\hline J & 1.70 & 1.7408 & $2 \%$ & 318.20 & 333.00 & $5 \%$ \\
\hline
\end{tabular}

Percentage increase of Sectional properties of Schifflirized angles

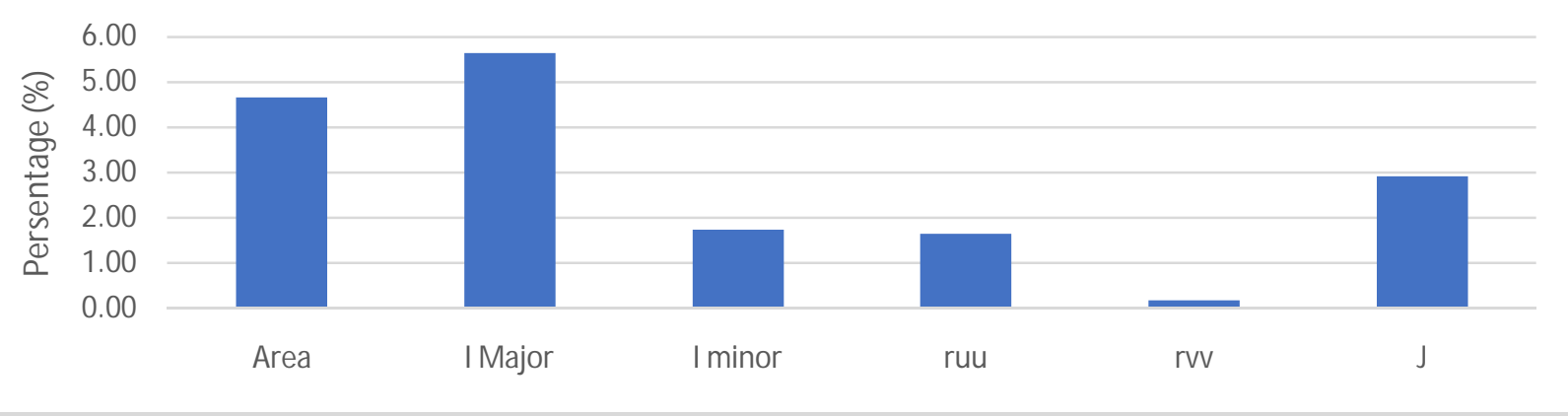

Figure 6:Comparison of sectional properties (Manual Vs E-Tabs)

Variation of sectional Areas

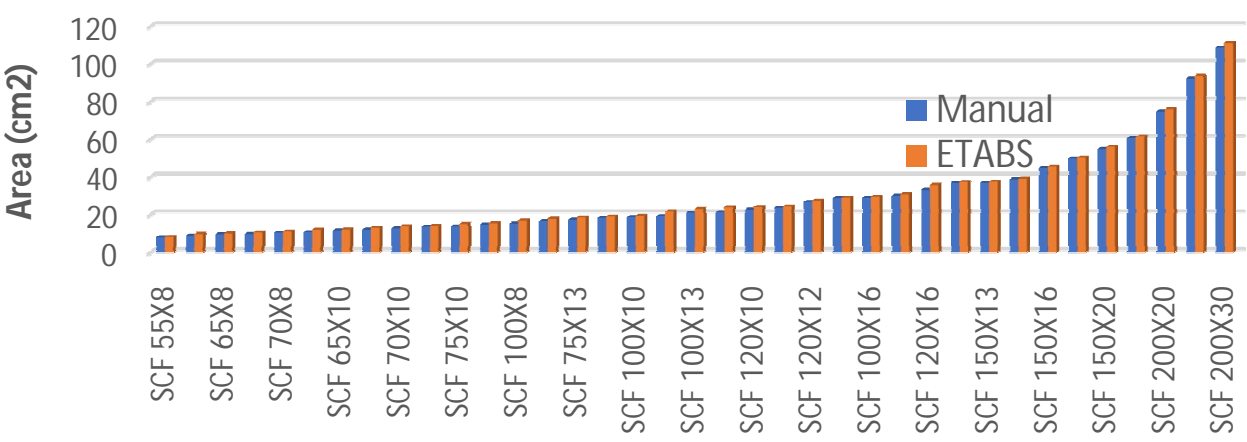

Schifflerized Section sizes

Figure 7: Variation of Sectional Area (Manual Vs E-Tabs) 
B.Ramesh et al., International Journal of Emerging Trends in Engineering Research, 8(10), October 2020, 6961 - 6968

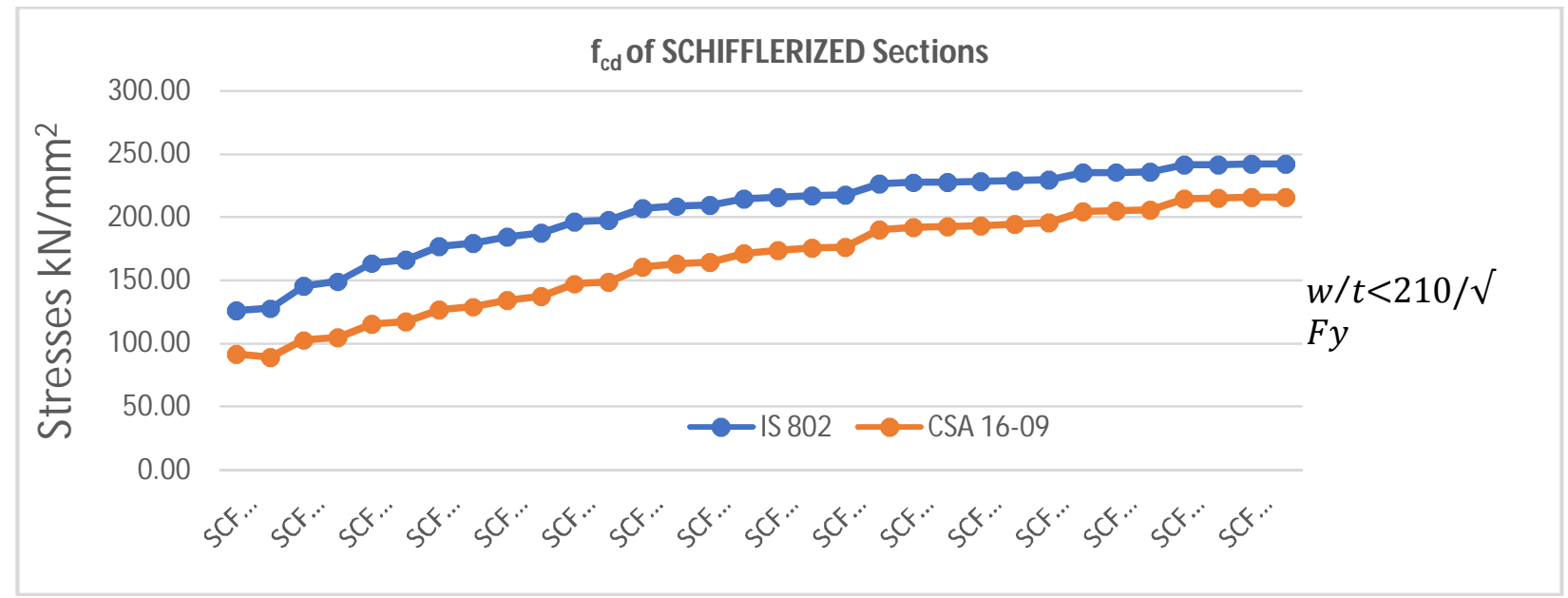

Figure 8: Variation of Stresses for 90o Angle Section (IS 802 Vs CSA 16-09)

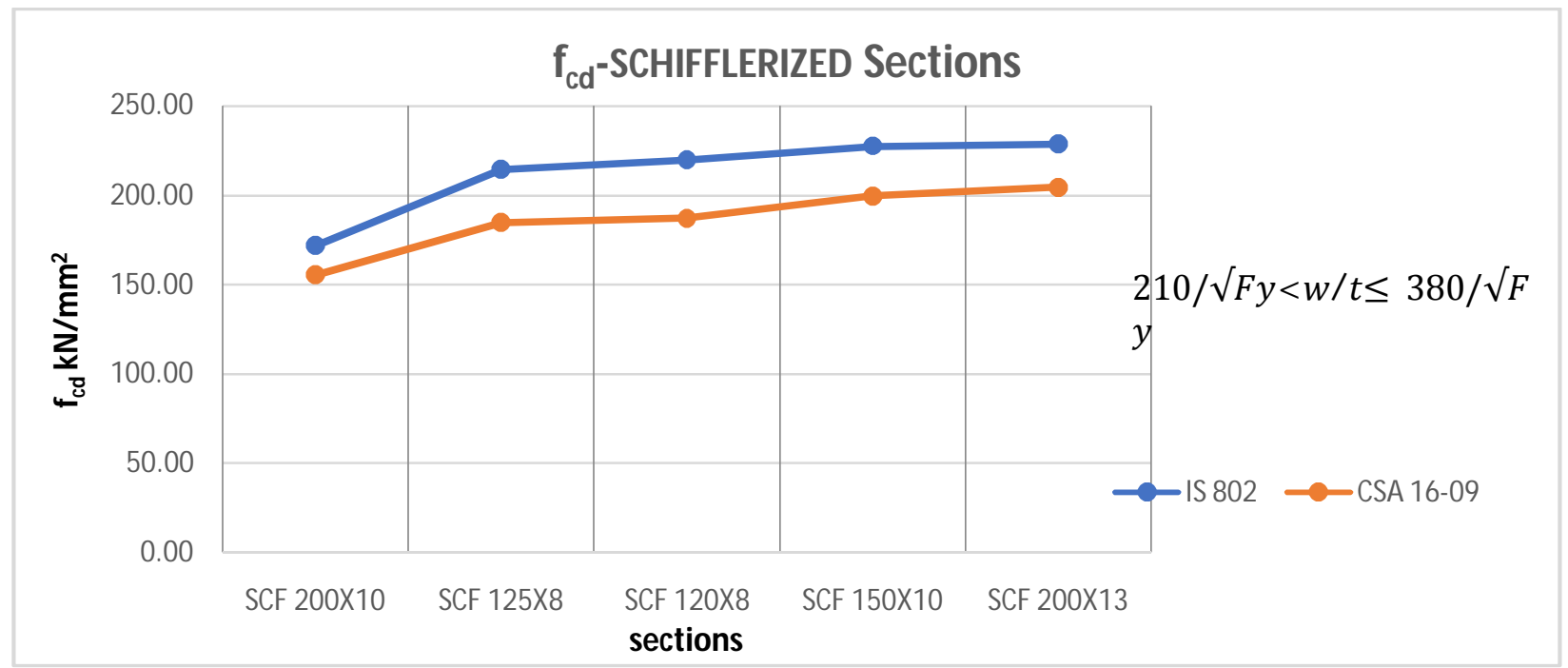

Figure 9: Variation of Stresses for schifflerized section (IS 802 Vs CSA 16-09)

\section{Factored Compressive strength-SCHIFFLERIZED Sections}

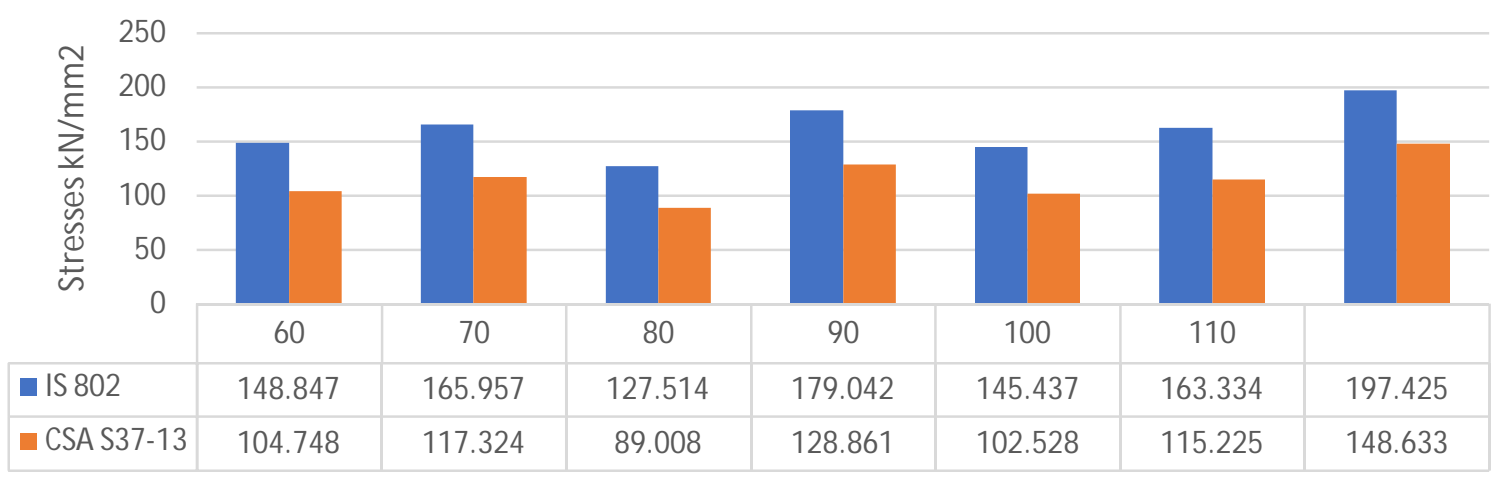

Figure 10: Factored Compressive strength in Schifflerized Sections (IS 802 Vs CSA 16-09) 
B.Ramesh et al., International Journal of Emerging Trends in Engineering Research, 8(10), October 2020, 6961 - 6968

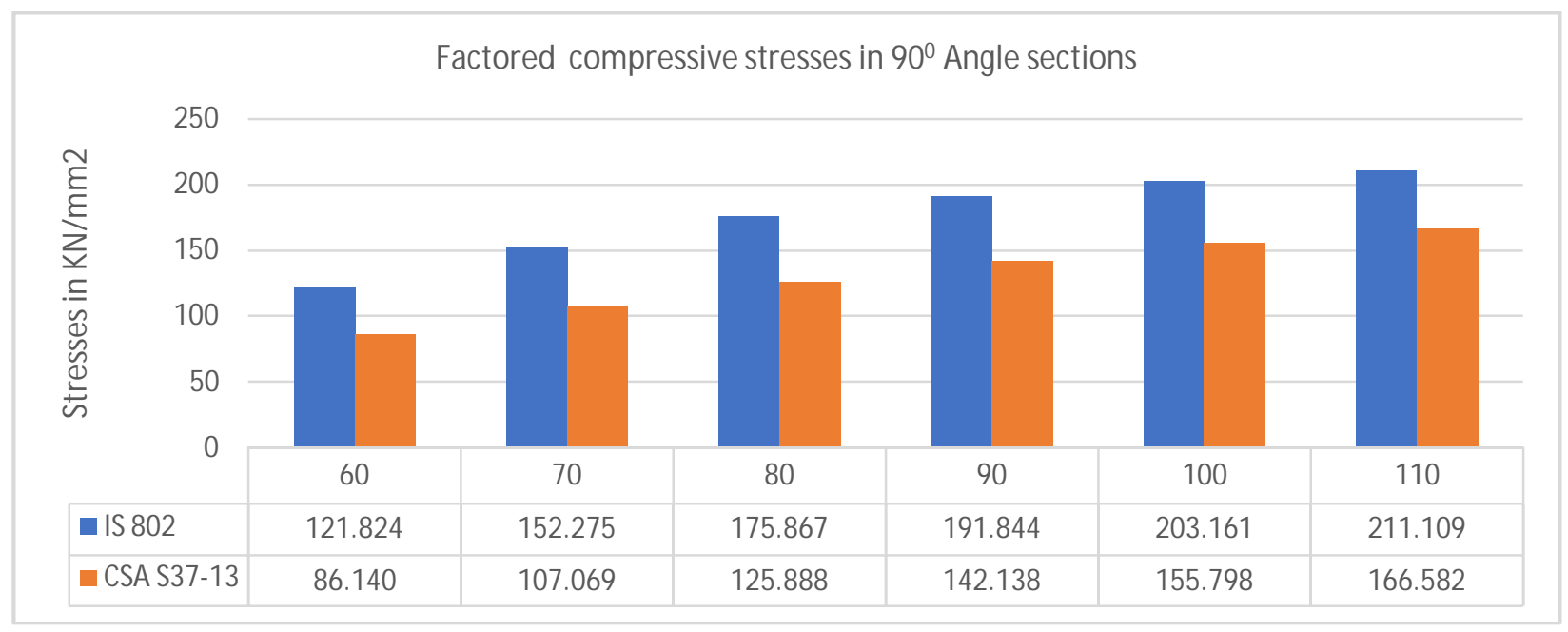

Figure 11: Factored Compressive strength in $90^{\circ}$ Angle Sections (IS 802 Vs CSA 16-09)

\subsection{Sectional properties:}

Area of $60^{\circ}$ schifflerized angle section calculated manually is less than $2 \%$, the radius of gyration about a minor axis is less than $0.5 \%$ and major axis is less than $1.5 \%$, the moment of inertia about the minor axis is less than $3 \%$ and moment of inertia about the major axis is less than $6 \%$ when compared with E-Tabs software values.

\section{DISCUSSIONS:}

The $60 \mathrm{~m}$ open triangular lattice tower has been modelled in E-tabs software programme. The sectional properties of all the fifty Schiffilirized angles are modelled using section designer in E-tabs. Secondly, for comparing the safety and economy point of view the same model is analyzed with the conventional angle sections for the profile legs and the bracings of the tower. The transverse critical wind loading analysis with longitudinal loading of the broken wire condition is considered for the tower geometry.

The geometric properties obtained from the E tabs software are compared with the closed-form solution(8). The variation of gust factor, the variation of wind pressure and the panel loads are depicted in the figures. With this, the following discussions are made. The factored strength of the elemental sections is found with the IS $802-2016$ recommendations and the CSA-16-09[20] procedure for all the profile leg sections are

1. Even though the wind pressure is constant along with the height of the tower, the panel loads are varied with

a. The variation of the Gust along with the height of the tower and

b. With the solidity ratio.

2. The factored compressive strength of the schifflerized sections are varied for three limiting conditions with the flat width to thickness ratio in
CSA16-07, however, the limiting values have some difference with other international codes,

3. The IS 802 code provisions are a specific requirement with the conventional angle systems and hollow sections only.

4. The factored strengths of conventional angle sections for the IS 802 code are from 121.824 to $211.109 \mathrm{kN}$ and for the Canadian code CSA9-16 are from $86.102 \mathrm{kN}$ to $166.582 \mathrm{kN}$

\section{CONCLUSIONS}

After simulating the $60 \mathrm{~m}$ high triangle TL tower modelling in E- tabs software, the wind loads are applied at the nodal points of the tower and the transverse wind load on the conductor for a $250 \mathrm{~m}$ span is applied at the cross arm level. The longitudinal broken wire load is applied to the tower as a critical torsion load. The wind loads are computed from the regional wind speed $50 \mathrm{~m} / \mathrm{s}$. And the panel loads are computed with the gust factor analysis.

While modelling the conventional angle sections, the geometric properties are directly chosen from the section database of the $\mathrm{E}$ tabs software, however, all the fifty (50)schifflerized angle sections are imported from the Auto Cad to E tabs software. Finally, the adaptability of the schifflerized angle sections is compared with the conventional angles. To compare these results geometric properties of the Schifflerized angles are computed from the equations of (8) and compared them from the output data of $\mathrm{E}$ tabs software. With the discussion made in the previous part and with the computed results the following conclusions can be drawn as follows.

1. The recommended equations for computing the factored compression strength of the conventional angle in IS $802-2016$ version are also applicable to Schifflerized angle sections without any modifications. Even though the code cannot propose any equations for Schifflerized angles. 
B.Ramesh et al., International Journal of Emerging Trends in Engineering Research, 8(10), October 2020, 6961 - 6968

2. To ascertain the IS 802 provisions for computing the factored compressive strength for schifflerized angles, a comparison has been made with CSA16-9 Standard which specified the strength equations for Schifflerized angles. The IS 802 provisions have slightly higher strength values over this standard, this occurred because of a slight difference in the ratio of width /thickness ratio parameter.

3. The computed sectional properties with the recommended equations in (8) are about $1 \%$ to $6 \%$ less than the E Tabs output sectional properties.

4. Even though the IS 802-2016 version prescribed the load-carrying capacity is influenced by the ratio of width to thickness ratio, the limiting ratios for the different buckling failure modes are not specified, but the equations are fair enough to apply for computing the factored compressive strength of schifflerized angle section.

5. The IS 802 factored compressive strengths recommend the more strength values than the Canadian standard on one side and the computational torsional flexural mode failure is little effect on the factored compressive strength computation with CAS standard equations, the Schifflerized angles can safely be adopted with IS $802-2016$ code provisions.

6. After satisfying with the above 1 to 5 conclusions the schiffilirized angle tower weight has measured 18 tonnes whereas conventional angle sections tower has 20 -tonne weight. Hence $10 \%$ less weight was obtained.

\section{REFERENCES}

[1] Balaji. KVGD,C. Rathikindi, B. Ramesh, andB. Santhosh Kumar. Influence of $\mathbf{k 4}$ and offshore wind velocity factors on $40 \mathrm{M}$ open lattice telecommunication tower,Journal of Engineering Science and Technology, Vol. 14, No 5, pp.2657-2669, 2019.

[2] Balaji, KVGD, Ramesh.B, Santhosh Kumar. B, Jnanchand, $S$ and C. K. Patnaikuni.Effect of Cyclonic Load Factor on Monopole Towers,Int. J. Eng. \& Technology $(U A E)$, Vol. 7, No. 4.17, pp. 75-84, 2018.

[3] B. Santhosh Kumar, B. Ramesh, K. V. G. D. Balaji, C. K. Patnaikuni, and S. Reynold, Along wind response of free-standing tri-pole lattice towers, Int. J. Civ. Eng. Technology, Vol. 9, No. 6, pp. 172-181, 2018.

[4] Seshu Madhava Rao.A,Murthy.S Madugula, Technical Note Geometric Properties of Schifflerized Angles, J. Constr. Steel Res, Vol. 18, pp. 71-83, 1991.

[5] Seshu Madhava Rao. A, Murthy K .S , Madugula, Gerard R .Monforton. Schifflerized Angle Struts ,ASCE,J, Strut, Eng, Vol 118 , No 7, 1992.

[6] M. K. S. Madugula and S. M. R. Adluri.Design of $\mathbf{6 0}^{0}$ equal-leg steel angles according to CSA standard S37-94, Can. J. Civ. Eng, Vol. 22, No. 3, pp. 603-610, 1995, doi: 10.1139/195-068.

[7] N. Prasad Rao, R. Balagopal, and R. P. Rokade.Buckling Behavior of Schifflerized Angle Sections, J. Inst. Eng. Ser. A, Vol. 101, No. 2, pp. 233-246, 2020, doi: 10.1007/s40030-020-00436-6.

[8] N. P. Rao, R. Balagopal, R. P. Rokade, and S. J. Mohan.Schifflerised angle sections for triangular-based communication towers, IES J. Part A Civ. Struct. Eng, Vol. 6, No. 3, pp. 189-198, 2013, doi: 10.1080/19373260.2012.757210.

[9] S. Chen and X. Wang.Buckling strength of single angle struts part 1: Angles subject to axial compression,Adv. Struct. Eng, Vol. 16, No. 6, pp. 1129-1138, 2013, doi:10.1260/1369-4332.16.6.1129.

[10] S. Chen and X. Wang.Buckling strength of single angle struts part 3: Cross-bracing in tower structure, Adv. Struct. Eng., Vol. 16, No. 6, pp. 1149-1160, 2013, doi: 10.1260/1369-4332.16.6.1149.

[11] M, R. Aydin. Elastic flexural and lateral-torsional buckling analysis of frames using finite elements, KSCE J. Civ. Eng., Vol. 14, No. $1, \quad$ pp. 25-31, 2009, doi: 10.1007/s12205-010-0025-8.

[12] J. P. Papangelis, N. S. Trahair, and G. J. Hancock.Elastic flexural-torsional buckling of structures by computer,Comput. Struct, Vol. 68, No. $1-3, \quad$ pp. 125-137, 1998, doi: 10.1016/S0045-7949(98)00037-6.

[13] B.Ramesh, Sharon Potireddy, Balaji, K.V.G.D and Santhosh Kumar B.Advantages of Monopole Transmission Tower With New Generation Conductors, Int. J. Adv. Res. Eng. Technol, Vol. 11, No. 3, pp. 79-90, 2020.

[14] Charan Rathikindi, B. Santosh Kumar, B.Ramesh and K. V. G. D. Balaji, Prominence of $\mathbf{k} 4$ factor in gust factor analysis for $30 \mathrm{~m} \& 60 \mathrm{~m}$ telecom towers, Int. J. Civ. Eng. Technol. Vol. 9, No. 8, pp. 1123-1131, 2018.

[15] B. Santhosh Kumar, K.V.G.D. Balaji, C. K. P. Perception of $k 4$ Factor in Cyclonic Region of India. International Journal of Engineering and Advanced Technology (IJEAT), Vol. 8, Issue 2s, pp. 206-208, 2018. 
B.Ramesh et al., International Journal of Emerging Trends in Engineering Research, 8(10), October 2020, 6961 - 6968

[16] John T. Tan.Transmission Line Performance Assessment and Design using MATLAB, Int. J. Emerging Trends in Eng. Research, Vol. 8, No. 9, pp. 5265-5272, 2020.

[17] Chebolu Sudheer Kumar,Chitti Babu Kapuganti,S. Eswara Rao, T. Santhosh Kumar, B. Ramesh, "Application of Last Planner System as Lean Construction Technique, Int. J. Emerging Trends in Eng. Research, Vol. 8, No. 9, pp. 6035-6041, 2020.

[18] E.TABS Software, Structural Software for Building Analysis and,Design, Computers and Structures, Inc,USA.,

[19] Bureau of Indian Standards, IS 802(Part1/Sec2):2016, Use of Structural Steel in Overhead Transmission Line Tower-Code of Practice, New Delhi.

[20] Canadian Standards Associations, S16-09, Design of Steel Structures.5060 Spectrum Way, Suite 100 Mississauga On L4w 5n6, Canada

[21] T, Santhosh Kumar. Effect on CO2 Cured Concrete Exposed to Sodium Sulphate.International Journal of Emerging Trends in Engineering Research, Vol. 8, No.7, pp. 3670-3674, 2020 , doi:10.30534/ijeter/2020/127872020 